\title{
Simulium (Chirostilbia) bifenestratum (Diptera, Simuliidae), a New Black-fly Species from the Atlantic Forest, State of São Paulo, Brazil
}

\author{
Neusa Hamada/ ${ }^{+}$, Mateus Pepinelli* \\ Coordenação de Pesquisas em Entomologia, Instituto Nacional de Pesquisas da Amazônia, Caixa Postal 478, 69011-970 \\ Manaus, AM, Brasil *Laboratório de Hidrobiologia, Universidade Federal de São Carlos, São Carlos, SP, Brasil
}

The larva, pupa, male, and female of Simulium bifenestratum $n$. sp. are described and illustrated. The pupae of the new species have 10 gill filaments, thick at their base and arranged in a three-dimensional way, surrounding the head and thorax. Its pupal cocoon is peculiar, not found in any of the known Brazilian black-fly species; it is very thick and hard with two openings in the anterior region. S. bifenestratum $n$. sp. was collected in one stream in the Bocaina mountain chain, Atlantic forest, in São José do Barreiro county, state of São Paulo, in a high (1500 m) natural grassland. Larvae and pupae were collected on the edges of small waterfalls and in places with-high speed laminar water flow, attached to the bedrock.

Key words: aquatic insects - black fly - Chirostilbia - Simuliidae - Bocaina - Brazil

In this paper we describe the larva, pupa, male, and female of a new species in the subgenus Chirostilbia, collected in a stream at the Bocaina mountain chain of the Atlantic forest, in the state of São Paulo. Coscarón (1987) divided this subgenus into two groups: Simulium subpallidum and S. pertinax; S. bifenestratum n. sp. can be placed on the latter group because of its black color, female with tarsal claws with a basal tooth and male gonostylus with no longitudinal ridge.

The new species has a very distinctive pupa, with two fenestrations in the cocoon. Crosskey (1990) reported that a similar cocoon was observed only in the northern hemisphere fauna, being found in some Simulium s.str. in Europe (e.g., S. colombaschense and S. reptans) in North America (e.g., S. jenningsi group), and in some Southeast Asian species. The pupal head plate also is very distinctive, with an elevated marginal area, especially the lateral region, forming a structure similar to a crown.

\section{MATERIALS AND METHODS}

Sampling was done on 16 May 2003, in Verde stream, São José do Barreiro county, state of São Paulo, Brazil. This place is located in the Bocaina mountain chain (Serra do Mar), in the Atlantic forest biome. Electrical conductivity (Cole-Parmer conductivimeter), $\mathrm{pH}$ (Cole-Parmer pHmeter), temperature (alcohol thermometer), geographical position (Garmin GPS) and stream width were measured at the sampled site.

Larvae and pupae were hand collected directly from the substrate (bedrock), under the water. Larvae were

Partial financial support: CNPq (process 550650/2001-6, 303652/2002-0) and PPI 1-3630 (MCT/Inpa)

${ }^{+}$Corresponding author. Fax: +55-92-642.8909. E-mail: nhamada@inpa.gov.br.

Received 9 October 2003

Accepted 18 December 2003 preserved in Carnoy solution ( 3 parts of absolute ethanol: 1 part of glacial acetic acid); pupae were preserved in absolute ethanol. Pharate adults were maintained alive in a covered plastic vial, with a piece of wet filter paper, to obtain the adults. After two days, the adults that emerge were preserved in $80 \%$ ethanol; pupae with pharate adults that did not emerged were also preserved in $80 \%$ ethanol. All specimens were preserved on ice in the field, and in the laboratory they were maintained refrigerated at $4^{\circ} \mathrm{C}$. In the laboratory, adults in $80 \%$ ethanol were dehydrated according to the technique of Sabrosky (1966), mounted in a triangle and pinned, with collection labels. Permanent slides, when needed, were mounted using Euparal ${ }^{\circledR}$ as the mounting medium, after being clarified in hot $95 \%$ lactic acid.

The holotype and some paratypes are deposited at the Instituto Nacional de Pesquisas da Amazônia (Inpa), Manaus, AM, Brazil; other paratypes are deposited at the Museu de Zoologia da Universidade de São Paulo (MZUSP), São Paulo and at the Laboratório de Hidrobiologia, Universidade Federal de São Carlos (UFSCAR), both in the state of São Paulo, Brazil.

\section{Simulium bifenestratum Hamada \& Pepinelli, New Species \\ Figs 1- 48}

FEMALE - General scutum color dark gray (Figs 1,2); body length 3.2-3.5 $\mathrm{mm}(\mathrm{n}=2)$; lateral thorax length 1-1.25 $\mathrm{mm}(\mathrm{n}=2)$. Wing, length $3.3 \mathrm{~mm}(\mathrm{n}=1)$, width $1.5 \mathrm{~mm}(\mathrm{n}=$ 1).

The number of reared females obtained was low $(\mathrm{n}=$ 2 ), and the emerged females did not have a well-preserved scutum as can be seen in Figs 1 and 2. In this way, scutum pattern could not be well defined in this description.

Frons, clypeus and occiput dark brown with silver pruinosity; frons longer than wide; fronto-ocular suture absent, fronto-ocular triangle as in Fig. 4. Antenna (0.6$0.7 \mathrm{~mm}$ ) with silver pubescence; pedicel, scape and proximal area of first flagellomere brownish yellow, following 
flagellomeres dark brown (Fig. 5). Palpus dark brown; sensory vesicle elongated, small (length less than $1 / 4$ of length of palpomere III), palpomere V 1.9 times as long as palpomeres III and IV. Mandible with 12-14 external serrations and 28-30 internal teeth. Lacinia with 24-25 retrorse teeth. Cibarium bare, with arms sclerotized (Fig. 3) bearing small serrations. Scutum dark gray with pale golden hairs, distributed unevenly except at the longitudinal median region where group of hairs form a line; 1 pair of small sub-rectangular silver spots, not well delimited, on the anterior margin, beside the medial line of hairs (Figs 1, 2). Anepisternum and katepisternum dark brown. Scutellum light brown, with black and golden hairs; postnotum brown. Wing veins, Sc and base of R with setae (Fig. 6). Foreleg (Fig. 7) with coxa, trochanter and medial to proximal region of femur light brown; distal region of tibia and all tarsal segments black. Middle leg (Fig. 8) with coxa, trochanter, femur and most of tibia light brown; distal end of tibia dark brown; basitarsus brown with $1 / 3$ distal region dark brown; other segments dark brown. Hind leg
(Fig. 9) with coxa dark brown; trochanter light brown; femur, tibia, and basitarsus light brown with distal end dark brown; following tarsal segments dark brown; calcipala as broad as long, not reaching pedisulcus (Fig. 10). Tarsal claws with basal thumb-like lobe (Fig. 11). Femora and tibiae with filiform setae. Abdominal sclerites dark brown; membranous areas light brown. Basal fringe with thin, long, golden hairs. Tergite II with silver pruinosity; tergites VI-IX with a varnish-like appearance. In lateral view, cercus round, anal lobe subtriangular (Fig. 12), in ventral view as in Fig. 13; hypogynial lobes (Fig. 15) subtriangular, without microtrichia, internal marginal area sclerotized. Genital fork (Fig. 14) with stem long, lateral arms well developed and with a large anterior process; the lateral arms form a sub-oval space. Spermatheca subspherical, with internal cuticular microspines, not forming a pattern; spermathecal duct and area of attachment unpigmented.

MALE - General body color black (Figs 16, 17), body length: $3.4 \mathrm{~mm}(\mathrm{n}=1)$; lateral thorax length: $1.04 \mathrm{~mm}(\mathrm{n}=1)$. Wing, length $3.1 \mathrm{~mm}(\mathrm{n}=1)$, width $1.35 \mathrm{~mm}(\mathrm{n}=1)$.
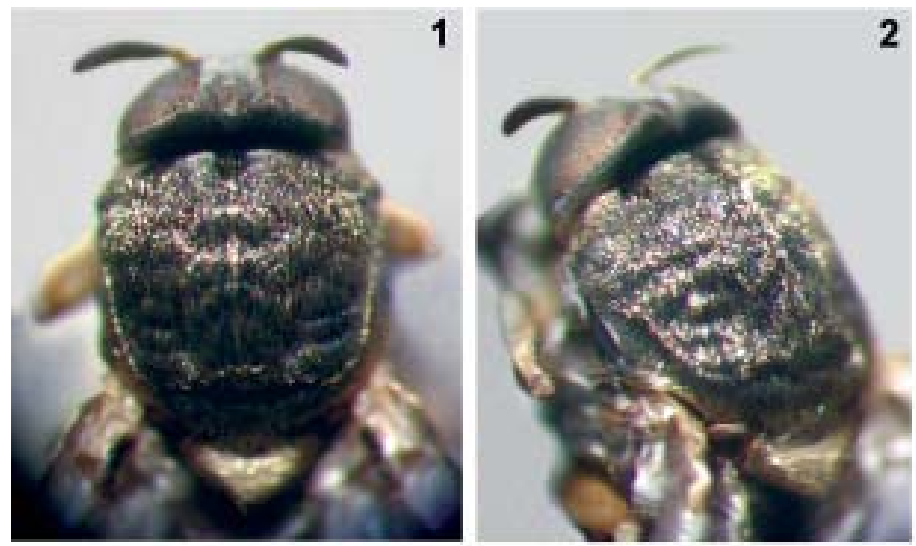

2

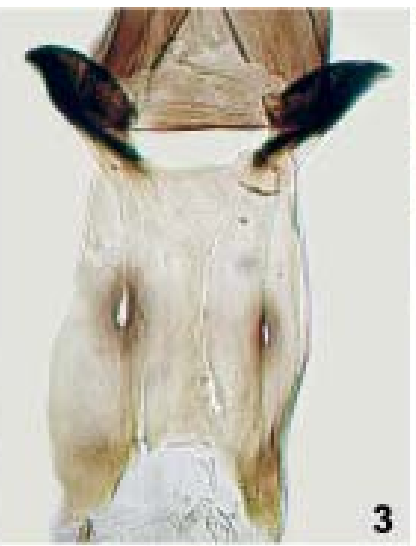

3
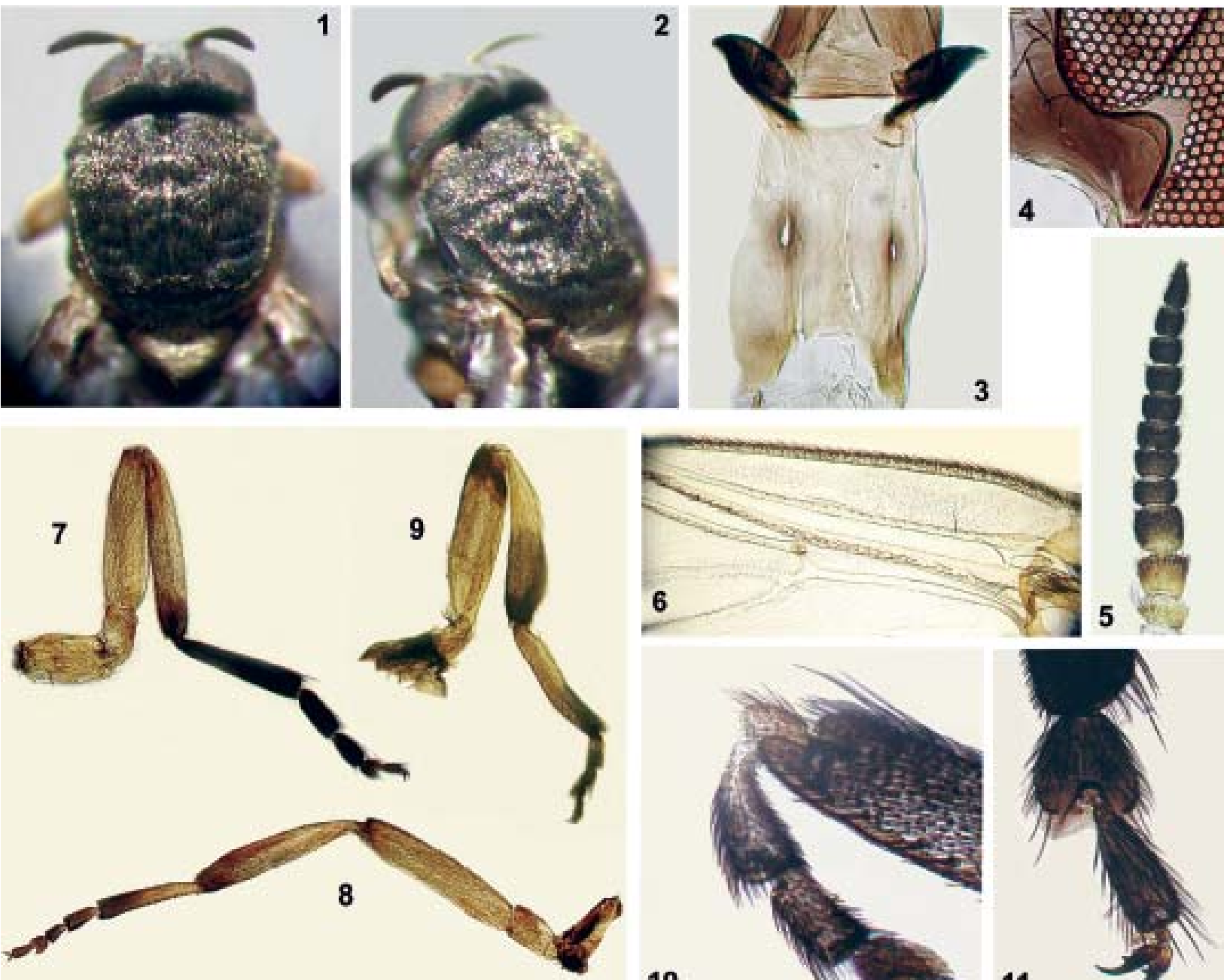

10

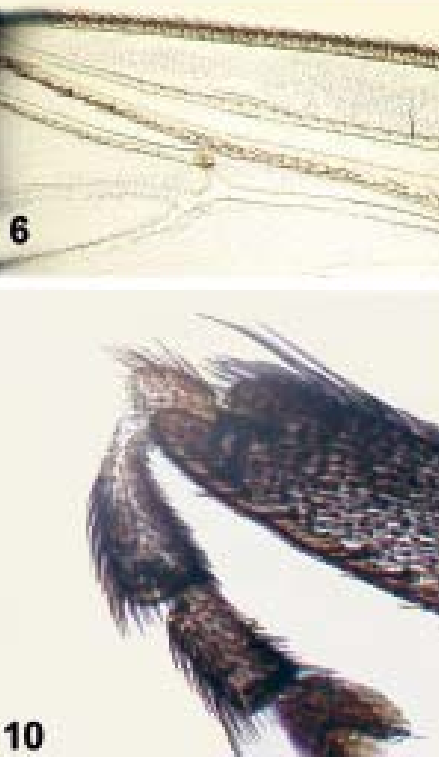

11

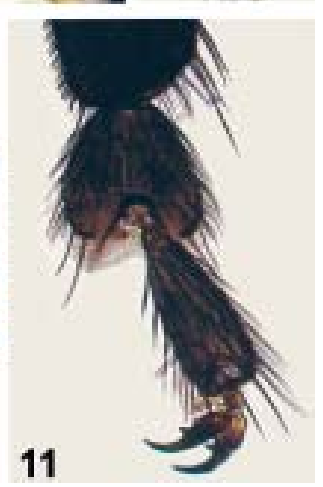

Female of Simulium bifenestratum n. sp. (Diptera: Simuliidae). Fig. 1: scutum, dorsal view. Fig. 2: scutum, dorso-lateral view. Fig. 3: cibarium. Fig. 4: fronto-ocular triangle. Fig. 5: antenna. Fig. 6: base of the wing. Fig. 7: fore leg. Fig. 8: middle leg. Fig. 9: hind leg. Fig. 10: calcipala and pedisulcus. Fig. 11: distal region of anterior leg showing the tarsal claw. 

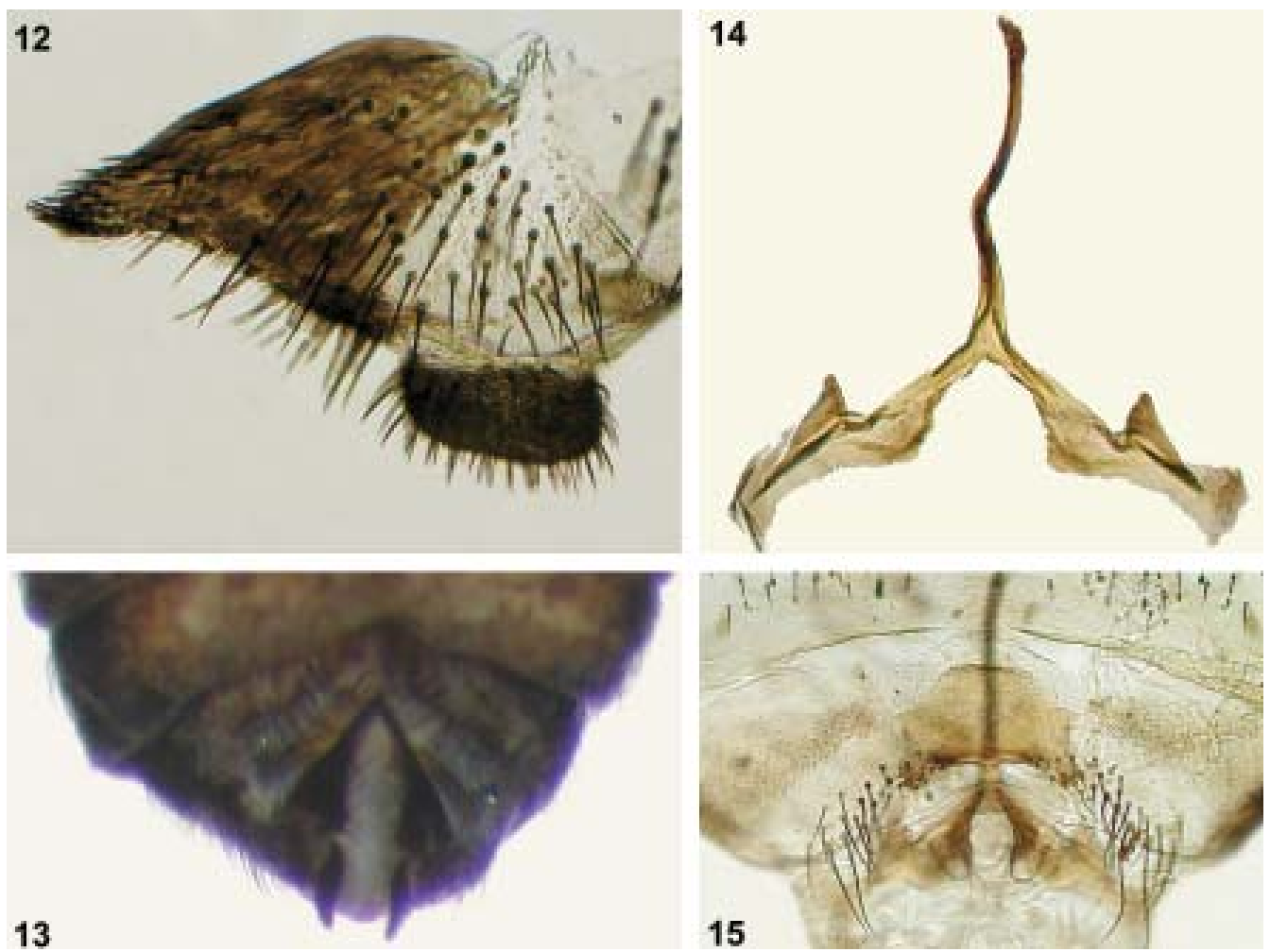

Female of Simulium bifenestratum n. sp. (Diptera: Simuliidae). Fig. 12: anal lobe and cercus, lateral view. Fig. 13: anal lobe and cercus, in situ. Fig. 14: genital fork. Fig. 15: hypogynial lobes, ventral view
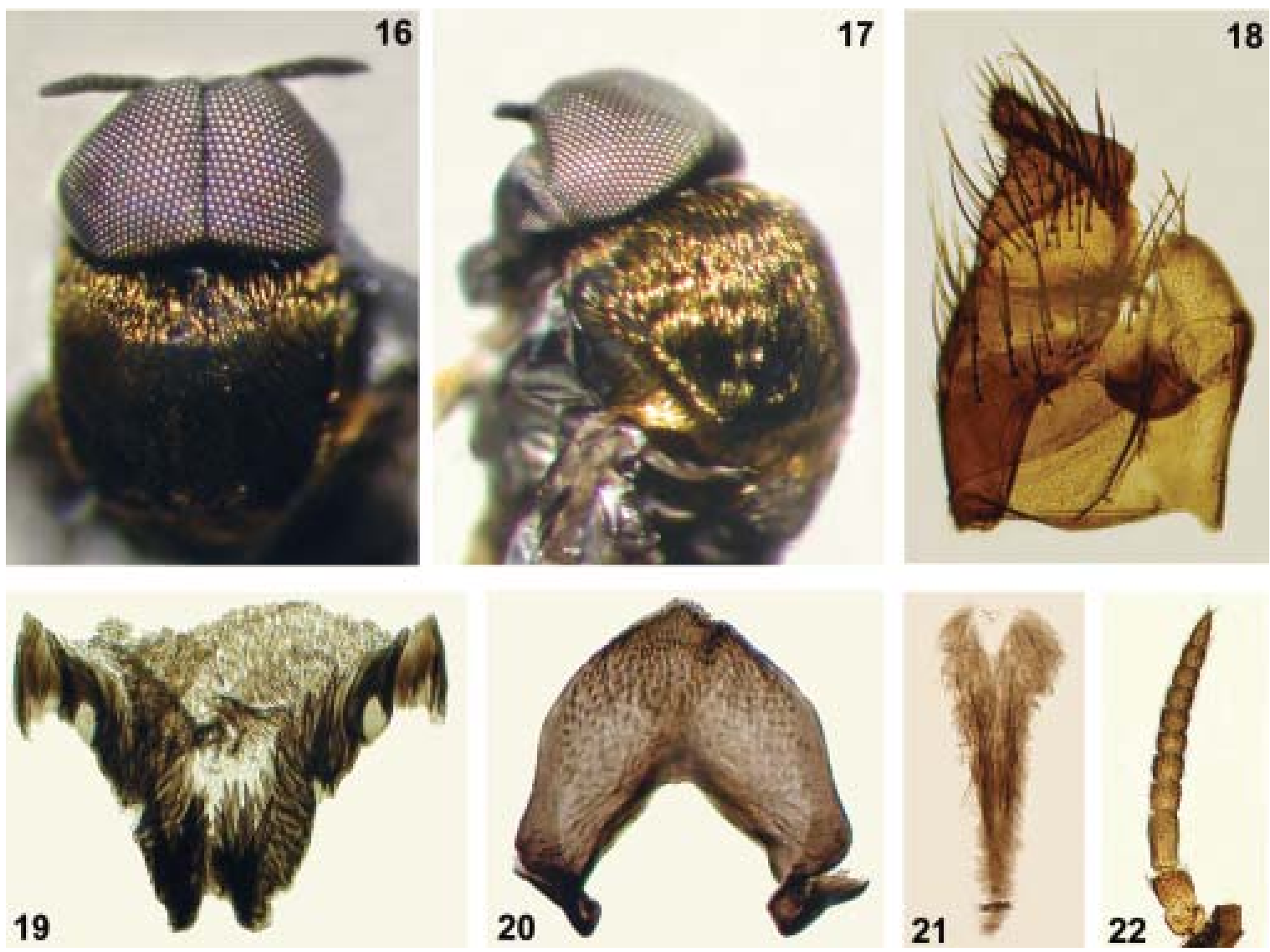

Male of Simulium bifenestratum n. sp. (Diptera: Simuliidae). Fig. 16: scutum, dorsal view. Fig. 17: scutum, dorso-lateral view. Fig. 18: gonocoxite and gonostylus. Fig. 19: paramere. Fig. 20: ventral plate. Fig. 21: median sclerite. Fig. 22: antenna 
Antenna 0.6-0.7 $\mathrm{mm}$ in length; pedicel and scape brownish yellow, flagellum dark brown (Fig. 22). Palpus dark brown, sensory vesicle small, occupying less than 1/ 5 of palpomere III; palpomere $\mathrm{V}$ about 1.8 times as long as palpomeres III and IV, sensory vesicle small, subspherical. Scutum black, with yellow golden hairs densely distrib- uted (Figs 16, 17). Scutellum dark brown, postnotum black. Anepisternum and katepisternum dark brown. Wing veins, $\mathrm{Sc}$ and base of $\mathrm{R}$ with setae. Legs with same color pattern as female. Abdominal tergites black; basal fringe with thin, long, black hairs; tergites II, V-VII, in lateral view, with silver pruinosity. Gonocoxite and gonostylus

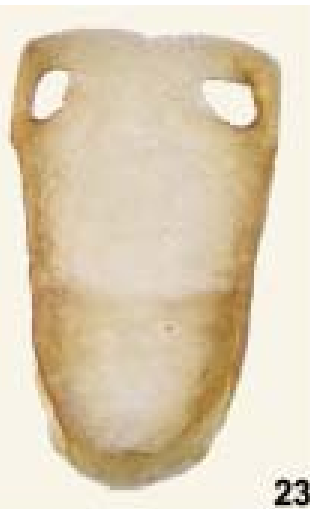

23

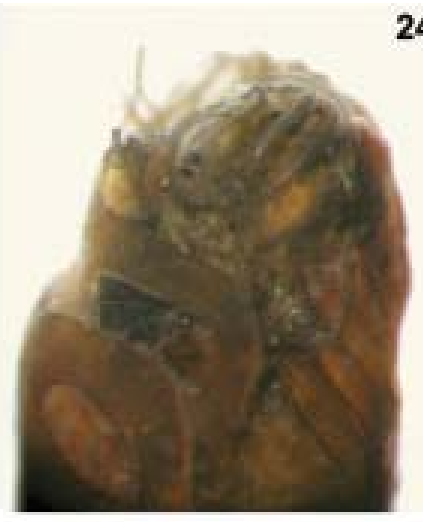

27
24

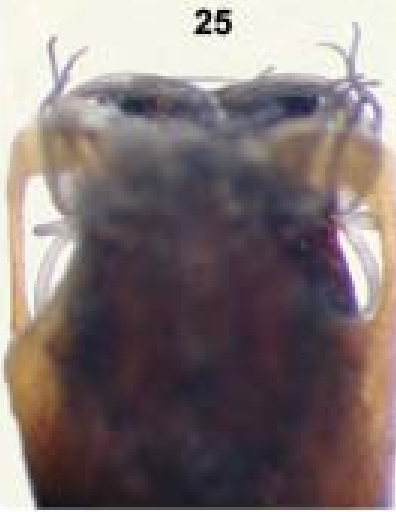

28

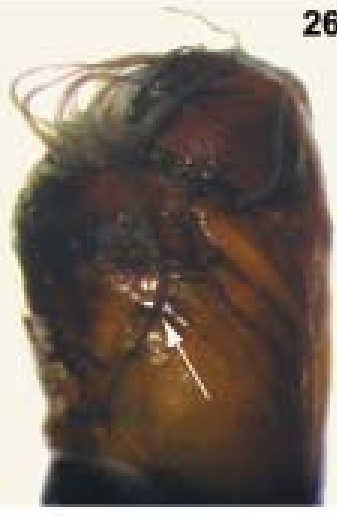

29
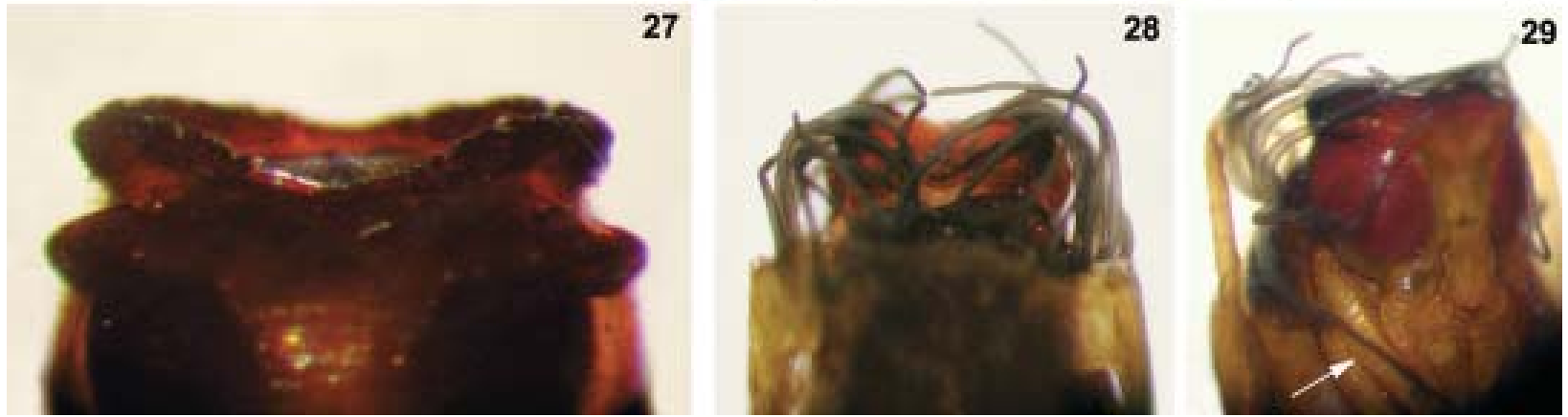

Pupae of Simulium bifenestratum n. sp. (Diptera: Simuliidae). Fig. 23: cocoon, dorsal view. Figs 24-25: anterior region, inside the cocoon. Fig. 26: anterior region, lateral view outside the cocoon. Fig. 27: head anterior region, ventral view. Fig. 28: anterior region, dorsal view. Fig. 29: head anterior region, ventro-lateral view. Arrows indicate gill filament along the thorax.
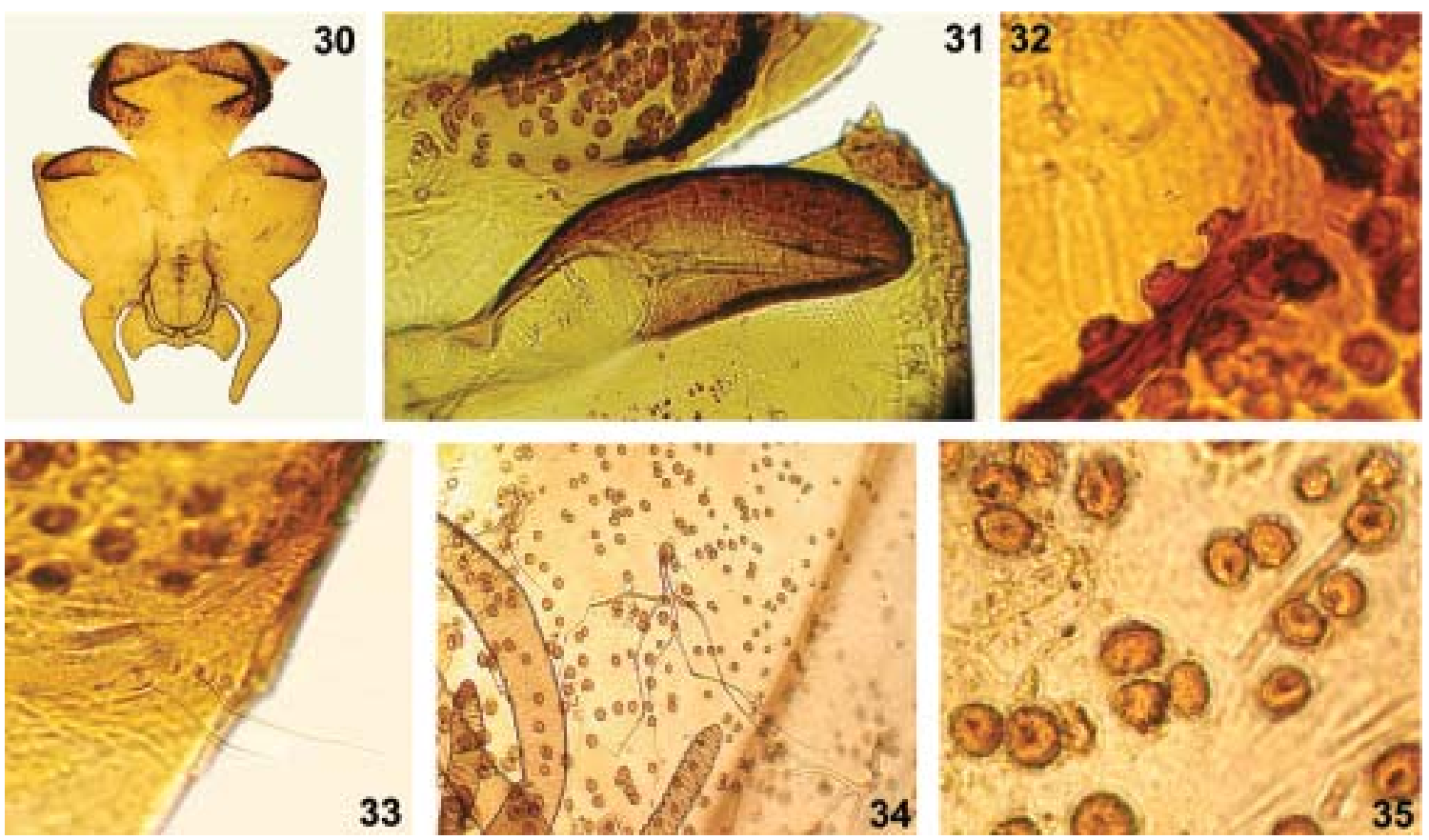

Pupae of Simulium bifenestratum n. sp. (Diptera: Simuliidae). Fig. 30: cephalic plate. Fig. 31: antennal sheaths, head frontal trichomes and tubercles. Fig. 32: head tubercles. Fig. 33: head frontal trichomes. Fig. 34: thoracic trichome. Fig. 35: thoracic tubercles 
black; gonocoxite subrectangular; gonostylus subquadrangular, 0.6 times as long as gonocoxite (Fig. 18). Ventral plate as in Fig. 20. Median sclerite (Fig. 21) elongated, with medial concavity. Paramere with spines (Fig. 19).

PUPA - Body length 3-4.3 mm ( $\overline{\mathrm{x}}=3.7 \mathrm{~mm}, \mathrm{n}=5)$. Cocoon (Fig. 23) slipper-shaped, very hard and thick, with 2 lateral openings. Length along dorsal surface $3.9-4.5 \mathrm{~mm}(\overline{\mathrm{x}}=4.2$ $\mathrm{mm}, \mathrm{n}=5)$; ventral surface $1.8-2.2 \mathrm{~mm}(\overline{\mathrm{x}}=1.96 \mathrm{~mm}, \mathrm{n}=5)$. Head projecting downward, with 2 pairs of frontal trichomes, each with 1-2 branches (Figs 31,33); 1 pair of facial trichomes with 2-3 branches; large rounded tubercles covered with small protuberances (Figs 31, 32, 33). Marginal area of cephalic plate elevated, especially lateral region, forming a structure similar to a crown (Figs 27, 30,31). Gills with 10 filaments, thicker at the base; four innermost filaments, thicker than the others (Fig. 26); 9 filament gills arranged tridimensionally, surrounding the head (Figs 24-26, 28, 29), 1 filament lies along the thorax (Figs 26,29). Thorax with large tubercles on the anterior to middle region, each with protuberances and a pointed structure on the superior side (Fig. 35); on the middle to posterior region, 2 types of tubercles, with and without pointed projections, that decrease in size; 5 pairs of trichomes with 3-9 branches (Fig. 34) and 1 pair of simple lateral trichomes. Abdomen as in Figs 36-38. Tergite I with 1 pair of simple or bifurcated setae sublaterally (Fig. 36a) and 2-3 pairs of small setae on the median region. Tergite II with 3 pairs of stout setae (Fig. 36b) and 3 thinner pairs sublaterally. Tergites III and IV each with 4 anteriorly directed pairs of hooks (Fig. 36c) on posterior mar-

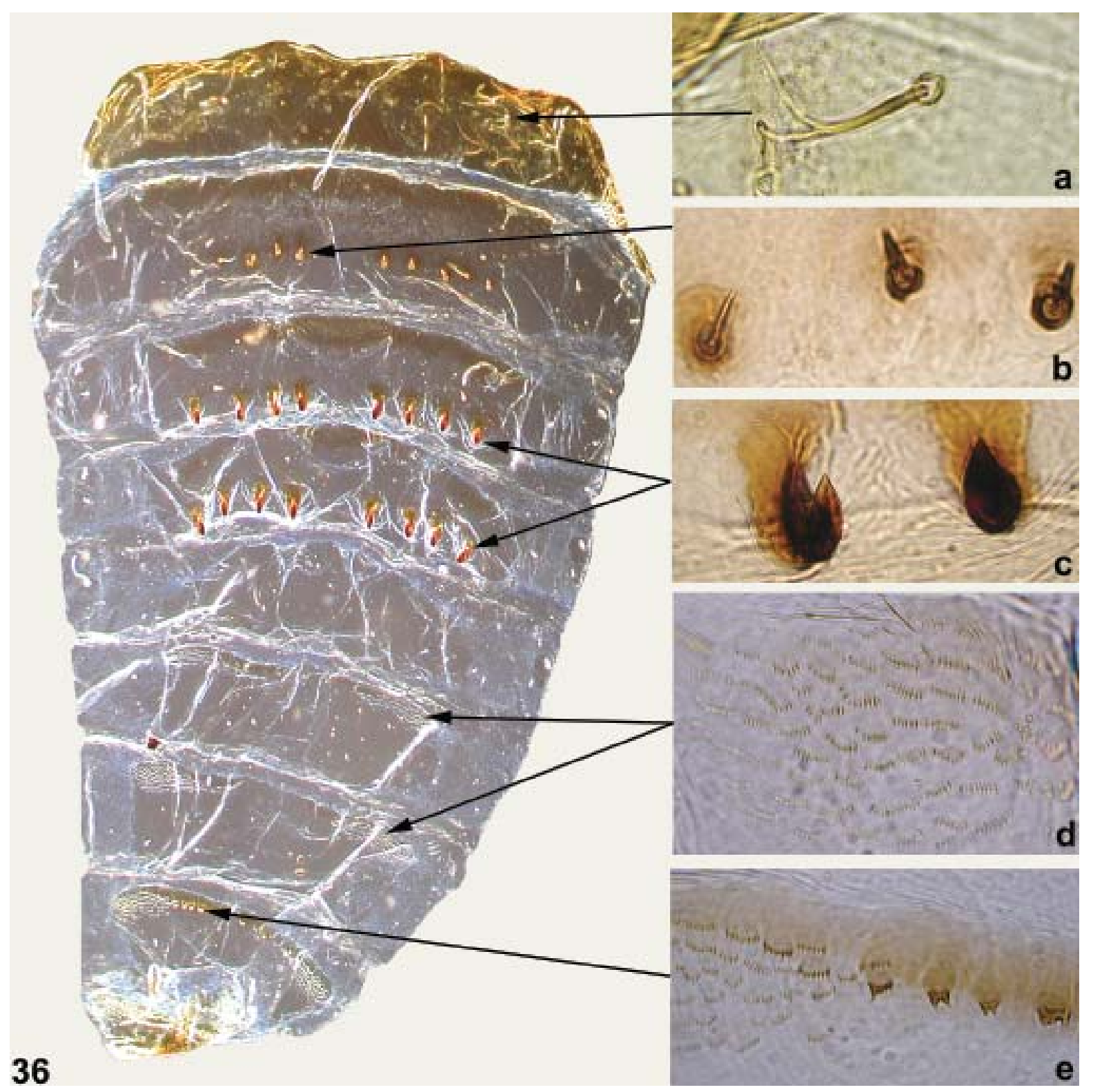

Fig. 36: dorsal view of abdomen of pupa of Simulium bifenestratum n. sp. (Diptera: Simuliidae). a-c: setae and hooks on tergites I-IV; de: comb of spines on tergites VI-VIII 
gin; 1 small seta between the 2 outermost hooks, on each side. Tergites I-IV with small, not pigmented, elongated spots, forming an open " $\mathrm{v}$ " pattern on the median region (Fig. 37). Tergite $V$ with 1 pair of stout seta laterally and 3 pairs of small submedian setae simple-trifid. Tergites VIIX with comb-like groups of fine posteriorly directed spines on anterior margins (Fig. 36d); tergites VIII and IX with stronger spines on the central anterior margin (Fig. 36e). Tergite VI with 2 pairs of small submedian, simple-bifid setae. Tergite IX with 1 pair of short terminal spines. Pleural membrane usually with 2-3 setae per segment. Sternites III-IX with anterior medial group of microspines (Fig. 38d); sternites IV-V with 2 plates divided by medial membranous area. Sternite IV with 3 pairs of submedian to lateral setae and 1 pair of stout hooks (simple or bifid) (Figs 38a, b). Sternite V with 2 pairs of lateral setae and 2 pairs of stout hooks (bifid or trifid) (Figs 38b, c). Sternites VI-VII with 4 plates, each divided by membranous areas; each plate bearing 1 hook (simple-trifid).

LARVA (final instar) - Length: $8.4-9 \mathrm{~mm}(\overline{\mathrm{x}}=8.8 \mathrm{~mm}, \mathrm{n}=$ 5); head capsule lateral length: $0.66 \mathrm{~mm}(0.66 \mathrm{~mm}, \mathrm{n}=5)$; dorsal width: $0.97 \mathrm{~mm}(\overline{\mathrm{x}}=0.97 \mathrm{~mm}, \mathrm{n}=5)$. General coloration dark brown (in Carnoy's solution). Head capsule (in dorsal view) with dark area on the mid to posterior region, forming a subtriangular pattern (Figs 39, 41); with simple or bifurcated setae. Cervical sclerites small, eliptical, free in the membrane (Figs 39, 41). Postgenal

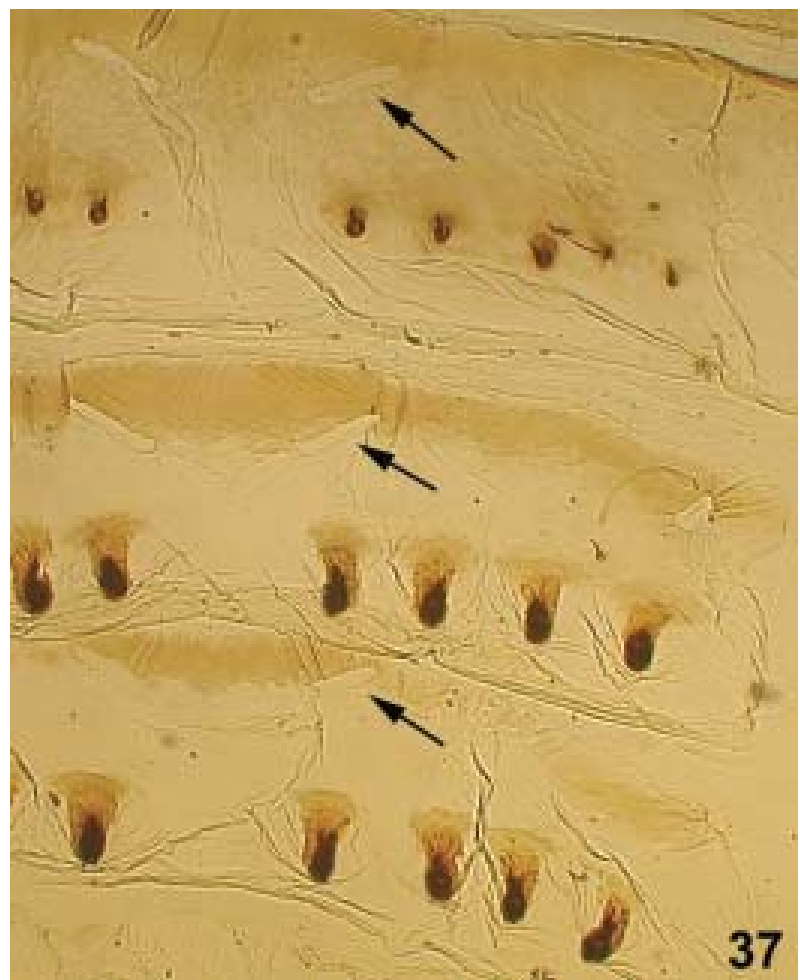

Fig. 37: dorsal view of part of abdominal tergites II-IV of pupa of Simulium bifenestratum n. sp. (Diptera: Simuliidae). Arrows indicate spots, elongated and not pigmented, on the median region of these tergites. cleft triangular, widest at base (Figs 40, 43), postgenal bridge 0.95 times as long as hypostoma (Fig. 43). Subesophageal ganglion pigmented (Fig. 40). Antenna as long as labral fan stalk (Fig. 39); distal, medial and proximal articles of different sizes (proportions of articles, proximal to distal, excluding apical sensillum, 1:1.81.9:0.8-0.9) (Fig. 42). Hypostoma (Fig. 44) median tooth shorter than the lateral teeth; two paralateral teeth; 5-7 lateral serrations and 8-9 setae (per side). Labral fan with 45-48 primary rays. Lateral mandibular process not seen. Body covered with simple setae. Cuticle in the antero-lateral region of the body, around the histoblast, not darkly pigmented, with small, white dots, each surrounding a seta (Fig. 45). Ventral posterior tubercle absent (Fig. 48). Anterodorsal arms of anal sclerite shorter in length than posteroventral arms (Fig. 46). Posterior proleg bearing $152-158$ rows $(\overline{\mathrm{X}}=154, \mathrm{n}=3)$ with $16-19$ hooks $(\overline{\mathrm{X}}=18, \mathrm{n}=6)$. Anal papillae with three branches, each with 20 - 26 lobes finger-shaped (Figs 47, 48).

TYPES - Holotype (Inpa) - Male (pinned), collected in Verde stream (22 $43^{\prime} \mathrm{S} ; 4^{\circ} 37^{\prime} \mathrm{W}$ ), Bocaina mountain chain, São José do Barreiro county, state of São Paulo, Brazil; collectors N Hamada and M Pepinelli, 16/V/2003. Paratypes - same locality, date and collector as holotype: Inpa - 1 pinned female, 2 pharate females, and 2 pharate males in permanent slide mounts with pinned thorax, 10 larvae and 10 pupae in $80 \%$ ethanol; MZUSP - 10 larvae and 10 pupae in $80 \%$ ethanol; UFSCAR - 1 pinned female, 1 pharate female, and 1 pharate male in permanent slide mount with pinned thorax, 10 larvae and 10 pupae in $80 \%$ ethanol.

ETYMOLOGY - The name of this species is derived from bis $(\mathrm{L})=$. two, and fenestra $(\mathrm{L})=$. window, in reference to the two openings on the anterior region of the pupal cocoon.

DIAGNOSIS - The last-instar larva of S. bifenestratum $\mathrm{n}$. sp. can be distinguished from the last-instar larvae of the other species in the subgenus Chirostilbia by the presence of white dots on the lateral region, around the gill histoblast (Fig. 45) and by the short length of the postgenal cleft (Fig. 43). The pupal cocoon is thick and hard, with two openings on the anterior region (Figs 23-25); no other known Brazilian black-fly species has a cocoon with this configuration. The pupal head plate also is very distinctive, having the marginal area, especially the lateral region, elevated (Figs 27,30), with large tubercles (Figs 31,32 ). Gill filaments are $10 \mathrm{in}$ number, thicker at their base than the apical region and arranged in a three-dimensional way around the head and thorax (Figs 24-26, 28, 29). Three species in the Chirostilbia subgenus have pupae with similar numbers of gill filaments (D'Andretta Jr 1954, PyDaniel 1987, Py-Daniel et al. 1988). Simulium distinctum Lutz, 1910 and Simulium riograndense Py-Daniel, Souza e Caldas, 1988 have 10 gill filaments, but they are thinner and arranged in a different way. Simulium friedlanderi Py-Daniel, 1987 has 11 gill filaments, shorter and thicker than those of the new species. Male genitalia are similar to those of $S$. distinctum and S. riograndense, but characters at the larval and pupal stages can easily distin- 


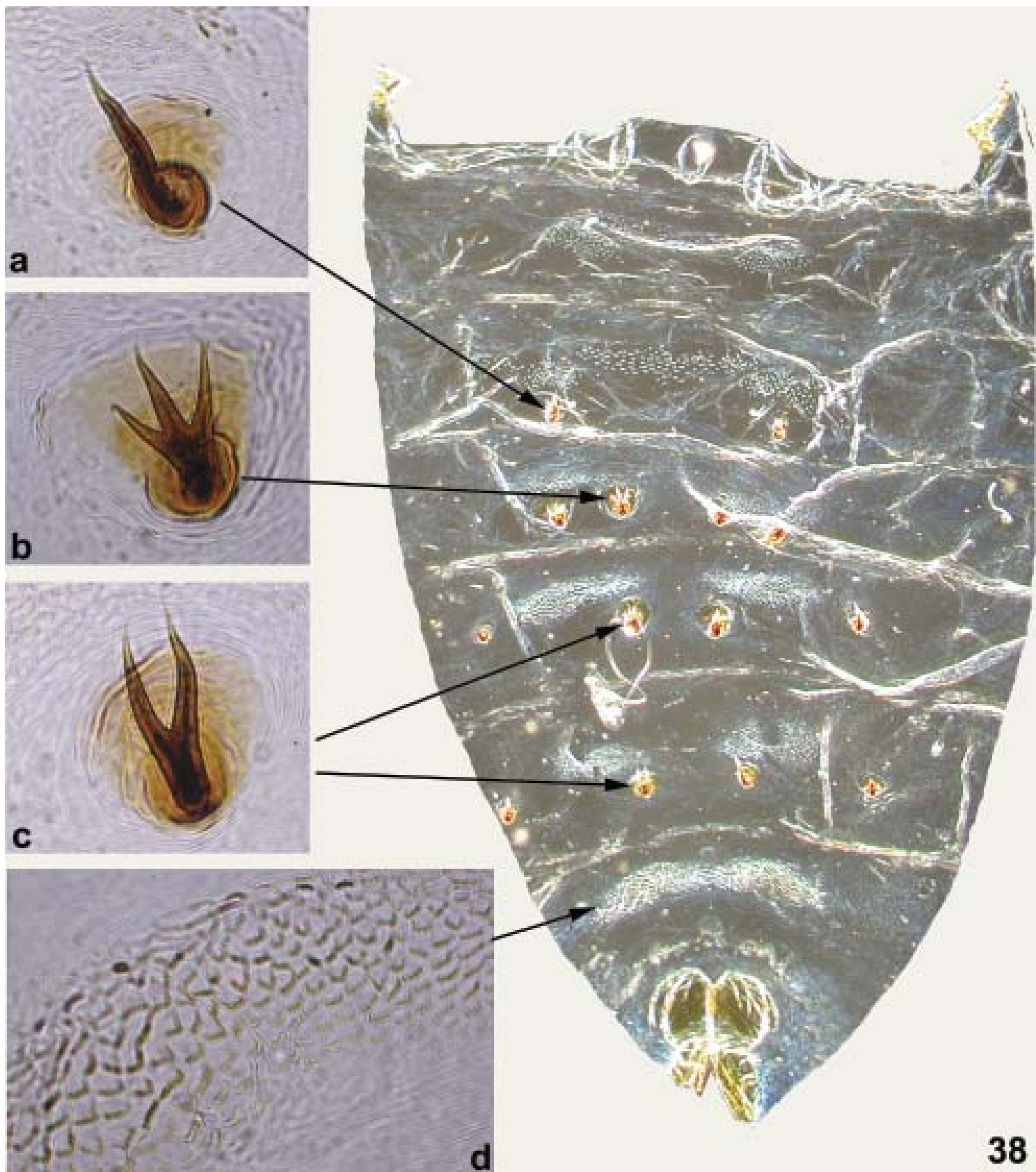

Fig. 38: ventral view of abdomen of pupa of Simulium bifenestratum n. sp. (Diptera: Simuliidae) - a-c: hooks on sternites IV-VII; d: comb of spines on tergite VIII

guish these species from the new species. Female scutum does not have the characteristic banding pattern of many of the species in the subgenus Chirostilbia, but the genitalia are similar to those of the females in this subgenus.

Bionomics - We have no information on the female feeding habits of this species; it was not collected biting humans during the field collection. Larvae and pupae were collected in one stream with bedrock, width around $10 \mathrm{~m}$, at high elevation $(1500 \mathrm{~m})$ in natural grassland. Water temperature was $10^{\circ} \mathrm{C}, \mathrm{pH}$ was 6.9 and electrical conductivity was below $20 \mu \mathrm{S} / \mathrm{cm}$.

\section{ACKNOWLEDGMENTS}

To Madalena Hamada Saji for the field work support and José Jayme for guiding us to the field site in São José do Barreiro. Sheyla RM Couceiro made the plates and Philip M Fearnside reviewed the manuscript.

\section{REFERENCES}

Coscarón S 1987. El Género Simulium Latreille en la Región Neotropical: Análisis de los Grupos Supraespecíficos, Especies que los Integran y Distribución Geográfica (Simuliidae, Diptera), Museu Paraense Emílio Goeldii, Coleção Emilie Snethlage, MCT-CNPq, 111 pp. 

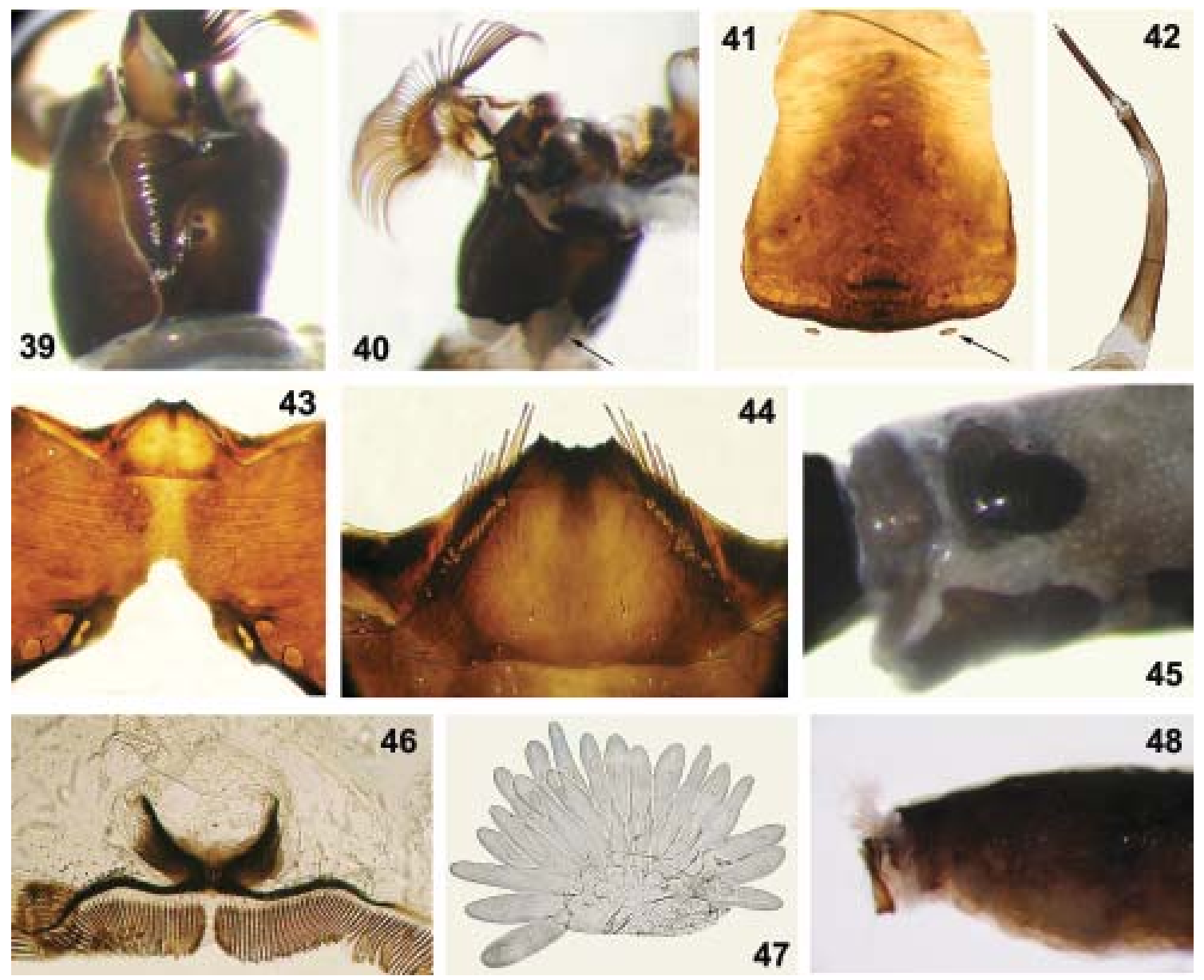

Larva of Simulium bifenestratum n. sp. (Diptera: Simuliidae). Fig. 39: head dorso-lateral view. Fig. 40: head ventro-lateral view, arrow indicates the pigmented subesophageal ganglion. Fig. 41: head dorsal view, arrow indicates the cervical sclerite. Fig. 42: antenna. Fig. 43: head ventral view. Fig. 44: hypostoma. Fig. 45: body anterior region, lateral view. Fig. 46: anal sclerite. Fig. 47: part of anal papillae. Fig. 48: body terminal region, lateral view

Crosskey RW 1990. The Natural History of Blackflies, John Wiley and Sons, Chichester, England, 711 pp.

D’Andretta Jr C 1954. Sobre Simulium distinctum Lutz, 1910 (Diptera: Simuliidae). Anais Fac Farm Odont USP 12: 63-66. Py-Daniel V 1987. Simuliidae (Diptera: Culicomorpha) no Brasil. V. Sobre o Simulium (Chirostilbia) friedlanderi $\mathrm{sp.}$ n. e revisão do Simulium (C.) laneportoi Vargas, 1941. Rev
Saúde Públ 21: 331-341.

Py-Daniel V, Souza MAT, Caldas EP 1988. Simuliidae (Diptera: Culicomorpha) no Brasil. III. Sobre o Simulium (Chirostilbia) sp. n. e revisão do Simulium (Chirostilbia) distinctum Lutz, 1910. Iheringia Ser Zool 67: 37-57.

Sabrosky CW 1966. Mounting insects from alcohol. Bull Am Entomol Soc 12: 349. 